\title{
Erratum to: Can magnetic resonance imaging accurately predict concordant pain provocation during provocative disc injection?
}

\author{
C. H. Kang • Yun Hwan Kim • S. H. Lee • R. Derby • \\ J. H. Kim • K. B. Chung • D. J. Sung
}

Published online: 13 November 2009

(C) ISS 2009

\section{Erratum to: Skeletal Radiol}

DOI: 10.1007/s00256-009-0709-7

Skeletal Radiol. 2009 Sep;38(9):877-85. Epub 2009 May 9.

On page 882 of the paper mentioned above, we have incorrectly implied that Drs. Modic and Bogduk were both co-authors of reference (42) and that they had the same opinion regarding HIZs. Reference 42 has been authored by N. Bogduk alone.We apologise to the readers of Skeletal Radiology and to Dr. Modic for this error.

The online version of the original article can be found under doi:10.1007/s00256-009-0709-7.

C. H. Kang · Y. Hwan Kim $(\bowtie) \cdot$ J. H. Kim • K. B. Chung •

D. J. Sung

Department of Radiology, Korea University Anam Hospital,

Korea University College of Medicine,

5-ga 126-1, Anam-dong, Sungbuk-gu,

Seoul 136-705, Korea

e-mail: mallecot@gmail.com

S. H. Lee

Department of Physical Medicine and Rehabilitation,

Korea University Anam Hospital,

Korea University College of Medicine,

Seoul, Korea

R. Derby

Spinal Diagnostics and Treatment Center,

Daly, CA, USA

R. Derby

Division of Physical Medicine and Rehabilitation,

Stanford University Medical Center,

Stanford, CA, USA 